\title{
Malapportionment and Multilateral Bargaining: An Experiment ${ }^{1}$
}

\author{
Emanuel I. Vespa \\ UC Santa Barbara
}

\begin{abstract}
Members of collective decision-making bodies often represent communities that differ in population sizes. Malapportionment results when decision-making power is not allocated evenly across the population. Two well known institutions with malapportionment have emerged: bicameralism and weighted voting. This paper studies experimentally how agenda setting power affects the distribution of resources, comparing across those two institutions. Conventional wisdom suggests that malapportionment favors scarcely populated states. I find that this is the case under weighted voting, but not necessarily in a bicameral system. In the later case, the allocation of agenda setting power can be used to eliminate distortions stemming from malapportionment.
\end{abstract}

\section{Introduction}

Members of collective decision-making bodies often represent communities which differ in population size. Such heterogeneities present a problem of committee design: how is decision-making power to be allocated in order to avoid the concern that larger communities systematically impose their will on the rest? Malapportionment results when decisionmaking power is not allocated evenly across the population. Currently, more than one-third of the legislatures in the democratic world were designed to reflect explicit malapportionment

\footnotetext{
${ }^{1}$ Research support from NSF Award ID \#0925897 and the Center for Experimental Social Science (CESS) at NYU is gratefully acknowledged. I have benefited from comments by Marina Agranov, Ryan Booth, Matt Embrey, Raquel Fernández, Gary Miller, Chloe Tergiman, Andrew Schotter, Alistair Wilson, Alessandro Lizzeri, seminar participants at the 2009 CREED-CESS Meeting in Experimental Economics, the Columbia Political Economy Breakfast, the NYU Seminar in Article Preparation, the 2009 International Meeting of the ESA, the 2010 Social Choice Meetings and the 2010 meetings of the Econometrics Society, and especially, Guillaume Fréchette. Remaining errors are mine. Contact: 2127 North Hall University of California, Santa Barbara, CA 93106, vespa@ucsb.edu.
} 
and two well-known institutions have emerged with this goal: bicameralism and weighted voting. Under bicameralism there is proportional representation in the house, but a fixed number of senators per state. Since proposals need approval from both chambers, the overall voting weight of a citizen from a small state is, by comparison, larger. For example, California's population is 65 times that of Wyoming, but it only has 18 times more votes in the US Congress. In a weighted voting system there is a unicameral committee: as states become more densely populated they are awarded more votes, but the increase in votes is less than proportional to the increase in population. For instance, while Germany is 207 times larger than Malta population-wise, its voting weight in the Council of the EU is only 9.6 times higher.

Although malapportionment of voting power is typically introduced to protect the rights of a minority, the voting system may also create unintended systematic differences in the distribution of resources. Empirical studies indicate a positive association between a geographic area's per-capita seats in the legislature and the share of public expenditures. ${ }^{2}$ Hence, less populated regions that are overrepresented would expect to receive higher allocations per-capita. ${ }^{3}$ However, economic theory highlights that the distribution of resources depends not only on voting power, but also on other prominent institutional features such as agenda-setting or proposal power. In fact, a key theoretical insight is that the allocation of proposal power can be used to control inequities under bicameralism, but not under weighted voting. In this paper, I test this hypothesis in the laboratory.

By design, small states enjoy an advantage in terms of voting power under bicameralism or weighted voting, but in either system there is freedom on how to allocate proposal power. Proposal power is captured, as in Baron and Ferejohn (1989), with recognition probabilities: the likelihood that each committee member is selected to be the agenda setter. Under bicameralism, proposal power is allocated evenly across the population (evenly apportioned) if the agenda-setter is selected with equal probability among house members. In this case, Ansolabehere et al. (2003) show that the final allocation of resources in per-capita terms is equal across states of different size. Yet when the agenda-setter is equally likely to be any senator (proposal power malapportioned), the prediction is an advantage for small states. Under weighted voting, proposal power is evenly apportioned if recognition probabilities

\footnotetext{
${ }^{2}$ See Lee and Oppenheimer (1999), Atlas et al. (1995), Hauk and Wacziarg (2007) and Knight (2008). The same regularity has been documented for other countries. See Samuels and Snyder (2001) for a survey.

${ }^{3}$ Anecdotal evidence is regularly in the press. For example, Lyptak (2013) compares Rutland County in Vermont to neighboring Washington County in New York. While both rural counties look alike in terms of demographics, Rutland County received four times more federal stimulus funding per capita in 2010. The difference is attributed to Vermont's higher per-capita reprentation in the US Senate. MacGillis (2009) and Lizza (2009) present examples involving health insurance, climate change legislation, and the allocation of Medicare resources.
} 
Proposal Power

Institution used to introduced Malapportionment of voting power

Bicameralism

Weighted Voting

\begin{tabular}{|cc}
\multicolumn{2}{|c}{ Proposal Power } \\
Evenly Apportioned & Malapportioned \\
\hline Yes & No \\
No & No
\end{tabular}

Table 1: Is the allocation of resources per capita equal across states of different size? Note: Proposal power is said to be evenly apportioned if it is allocated evenly across the population and malapportioned if it favors scarcely populated regions. Under bicameralism proposal power is evenly apportioned (malapportioned) when the agenda-setter is selected only among house (senate) members. Under weighted voting proposal power is evenly apportioned (malapportioned) if the likelihood of being selected as the agenda-setter depends on population (voting) weights.

are equal to population weights, and malapportioned if equal to voting weights. For this institution, following Snyder et al. (2005) it is possible to show that regardless of how proposal power is allocated, the voting advantage for small states will materialize in higher resources per capita.

The main hypothesis -outlined in Table 1 as a reference- predicts that both, the allocation of proposal power and the institution affect the distribution of resources. An empirical test requires variation in institutions and in the allocation of proposal power. Cross-country comparisons allow studying institutional differences, but also add significant unobserved heterogeneities and measurement problems. On the other hand, in the laboratory it is possible to isolate other channels, reproduce the theoretical environment, and focus on studying the predicted influence of proposal power. Table 1 also captures the idea behind the experimental design: changing the allocation of proposal power across institutions.

The experimental data is qualitatively in line with the hypothesis that proposal power can be used to equalize per-capita allocations under bicameralism, but not under weighted voting. There is no difference across state sizes if proposal power is evenly apportioned under bicameralism. On the other hand, small states enjoy a per-capita advantage under weighted voting, or if proposal power is malapportioned under bicameralism. While the evidence supports the comparative statics, there are differences with the predictions. First, quantitatively, small-state advantages are in all cases lower than predicted. In other words, the prediction overestimates the importance of a voting advantage. In addition, there is no clear evidence in favor of the underlying mechanism.

An auspicious finding is that the deviations from the theoretical mechanism are not random, but related to two patterns that are common to all treatments. First, regardless of the size of the state, the average allocation to coalition members other than the agenda setter is between 80 and $90 \%$ of the equal split. These values are higher than predicted by the theory, which claims that the agenda setter can extract more resources from others. However, observed shares are comparable to reports for bilateral bargaining experiments (see Roth 1995) and suggest the presence of a simple underlying division rule that arises despite 

against one common view of malapportionment (Lee 2000), according to which senators from smaller states are less costly to include in a coalition because the size of their constituency is smaller.

The second pattern is the lack of an endogenous response to how proposal power is allocated. Theoretically, the agenda-setter is predicted to retain a large share of the budget, and states with higher recognition probabilities would enjoy this advantage more often. In equilibrium, this force is compensated by an endogenous response in coalition formation: states with higher recognition probabilities are invited less often to be part of the minimum winning coalition when they are not the agenda-setter. However, in the data there is no evidence that subjects adjust in this manner. This implies that exogenous advantages in recognition probabilities will translate into extra shares of the budget. Under bicameralism, when proposal power is in the house there are no exogenous advantages, but when the proposer is selected equally among senators small states will accrue a benefit. Under weighted voting, large states get an advantage from higher recognition probabilities. This effect reduces the voting advantage for small states, but the gains are not enough to compensate and equalize per-capita shares. ${ }^{4}$

The experimental design builds on the literature that investigates legislative bargaining in the laboratory. ${ }^{5}$ This paper focuses on the effect of proposal power on resource allocation and on its interaction with malapportioned voting power. Other papers have recently studied different aspects of committee bargaining. Some such examples include: Christiansen et al. (2014) (adds a policy dimension), Drouvelis et al. (2010) (committee size in weighted voting), Fréchette et al. (2005b) (nominal voting power), Fréchette et al. (2010) (a public good), Tergiman (2015) (vote of confidence procedure), Kagel et al. (2010) (veto power) and Agranov and Tergiman (2014) (communication).

\section{Experimental Design and Hypotheses}

The experiment studies the allocation decisions of a committee that represents a total population of size $n$ distributed in $m$ states. The task is to distribute a budget of size $P$, assumed equal to 1 . The decision will be made following a closed-rule alternating-offer bargaining protocol:

\footnotetext{
${ }^{4}$ To study the effect of recognition probabilities more broadly I conduct an extra treatment with extreme probabilities of recognition for L states. Only in this extreme case is it possible for L states to have per-capita shares comparable to those of small states.

${ }^{5}$ McKelvey (1991), Fréchette et al. (2003), and Diermeier and Morton (2004) study the basic properties of the Baron and Ferejohn environment and Fréchette et al. (2005a) compare across bargaining protocols.
} 

cation of the budget. One of these proposals is selected to be voted on and the member whose proposal was selected is referred to as the "proposer. ${ }^{6}$

2. Voting: All members of the committee simultaneously vote on the proposal with no possibility of amendment. If the proposal is supported by a winning coalition, the game is over. If the proposal is rejected, there is a new call for proposals (a new stage) and the process repeats itself. ${ }^{7}$

An institution specifies how voting power is allocated. Under bicameralism, committee members are divided into two sub-committees: the house and the senate. In the house representation is proportional to population, while in the senate all states have equal representation. Members have one vote and a simple majority in both sub-committees is required for a proposal to pass. Under weighted voting, each state has one representative in a unicameral setting, but states differ in the number of votes they control. A proposal needs a simple majority of the total votes in order to pass.

This section describes two experiments, one for each institution. Within each experiment there are treatments on the proposal rule, which specifies the probability with which a proposal is selected. The focus is on whether proposal power is allocated evenly across the population or not. The main hypotheses presented at the end of the section claim that the allocation of proposal power does affect how resources are distributed under bicameralism, but not under weighted voting.

For each institution I will now illustrate the theoretical predictions for the parametrization taken to the laboratory, which involves an underlying population of size five $(n=5)$ organized in three states $(m=3)$. For further detail on the theoretical background the reader is referred to Ansolabehere et al. (2003) and Snyder et al. (2005) (AST and STA, respectively, from now on).

\subsection{Bicameralism Experiment}

There are two Small (population size 1) and one Large (population size 3) states, characterized by their type $t \in\{S, L\}$. Thus, there is a total of five representatives in the house (one per district or unit of population) and three senators (one per state). ${ }^{8}$ The committee

\footnotetext{
${ }^{6}$ In the closed-rule procedure of Baron and Ferejohn (1989), the proposer is chosen first and then is asked to submit a proposal. Theoretically, this is equivalent to asking for proposals first and then randomly selecting one, which is standard in experimental applications to gather more data (see Fréchette et al. (2003)). Empirically, this procedure may introduce behavioral differences if, for example, a subject whose proposal is not selected conditions her vote on the amount her own proposal allocated to the actual proposer. The evidence in Table 11 of Online Appendix B indicates that such effects are not present in the data.

${ }^{7}$ Ansolabehere et al. (2003) study the case with no discounting between stages. I will also focus on the no discounting case in order to keep the design as simple as possible.

${ }^{8}$ House representatives will be referred to using female pronouns. Male pronouns will be used for senators.
} 

vector that specifies the share of the pie allocated to each of the five districts. The experiment consists of a between-subjects design with two treatments, depending on how proposal power is allocated.

- Bic Even Treatment: Proposal power is evenly apportioned -only house members submit proposals and one is randomly chosen (with probability $1 / 5$ ).

- Bic Malap Treatment: Proposal power is malapportioned -only senate members submit proposals and one is randomly chosen (with probability $1 / 3$ ).

In both treatments, a proposal that was randomly selected passes if it receives a simple majority in both sub-committees. The payoff to representatives is equal to the share allocated to their district. The payoffs to a type- $t$ senator will be given by the median allocation in his state. In $\mathrm{S}$ states the payoff is simply the allocation to the only district in the state. The payoff to the L senator is determined by the median share allocated to districts in his state. $^{9}$

\section{Theoretical predictions}

AST show that if proposal power is evenly apportioned, the Symmetric Stationary Subgame Perfect Equilibrium (SSSPE) involves a unique payoff distribution. The continuation value $\left(v_{t}\right)$ represents the expected payoff for a committee member before the identity of the proposer is revealed. A member will vote in favor of a proposal if they are allocated at least $v_{t}$. To compute the continuation value, consider what happens if a representative rejects a proposal in the current stage. With probability $\frac{1}{5}$ she will be the proposer next stage in which case her payoff will be $1-\underline{v}_{t}$, where $\underline{v}_{t}$ is the minimum payment to others that achieves a winning coalition. With probability $\frac{4}{5}$ she is not the proposer and she may or may not be included in the winning coalition. Let $q_{t}$ represent the probability that a member of type $t$ is included in the coalition when she is not the proposer -I will refer to such coalition members as non-proposers. If she is included in the winning coalition, she will be offered $v_{t}$ to get her support. Overall, this indicates that $v_{t}=\frac{1}{5}\left(1-\underline{v}_{t}\right)+\frac{4}{5} q_{t} v_{t}$. The following result is a special case of AST's Proposition 1.

\footnotetext{
${ }^{9}$ The underlying rationale for these preferences is that both, senators and representatives, want to maximize the utility of their constituency's median voter, and voters are assumed to have identical, quasi-linear preferences. Since no spillovers among districts exist, each representative will simply maximize the share going to her district. AST assume that a senator cares not only about the total sum of money allocated to his region, but also about its distribution. They capture this idea with payoffs given by the median allocation to the state. See Kalandrakis (2004) for an alternative specification of senators' payoffs, but similar comparative statics on the change in recognition probabilities.
} 
Result 1. If proposal power is evenly apportioned, then any SSSPE satisfies $v_{t}=\frac{1}{n}=\frac{1}{5}$ for all $t$.

Districts in S states do not expect higher payoffs than districts in the L state and cannot take advantage from their overrepresentation in the senate. To see why, consider an L representative at the proposal stage. ${ }^{10}$ She would always include herself in the minimum winning coalition (MWC), but she has several alternatives to include others. For example, she could include one of the other two L representatives (getting the support of the L senator) and either of the two S states -I will refer to this coalition type as LLS. ${ }^{11}$ Or, instead, she could form a coalition with the two S states -I will refer to this coalition type as LSS. This means that no representative or senator is indispensable to form a MWC. If any member was more expensive to include in the MWC, then the proposer would have an incentive to form a MWC that excludes that member. In equilibrium, the cost of including any member is equal across $t$.

For the equilibrium $v_{t}$ not to depend on $t$, a specific balance of coalition types is required. To see why, suppose that $v_{t}$ is the same across districts but that proposers only form LSS coalition types. This would mean that $\mathrm{S}$ districts are more likely to receive a payment than L districts and hence their expected payoff would be higher -a contradiction. In equilibrium, the LLS (LSS) coalition type should be formed with probability 80 (20) percent. In turn, this means that in equilibrium $q_{S}=q_{L}=\frac{1}{2} \cdot{ }^{12}$

The equality in continuation values across $t$ does not hold if proposal power is in the senate. In this case, proposal power changes with state size: it is as if the likelihood of being the proposer is $\frac{1}{3}$ for an $\mathrm{S}$ district, but $\frac{2}{9}$ for each L district. ${ }^{13}$ This means that upon rejecting a proposal, $\mathrm{S}$ representatives are more likely to have their senator be a proposer next time. In equilibrium, to deter them from rejecting a proposal the continuation value for $\mathrm{S}$ will be higher.

Result 2. If proposal power is malapportioned, then at any SSSPE $v_{S}=\frac{2}{7}>\frac{1}{7}=v_{L} \cdot{ }^{14}$

\footnotetext{
${ }^{10}$ The same argument next holds if the proposer is an $\mathrm{S}$ representative.

${ }^{11}$ If two of the three districts in the L state are getting a payoff equal to the continuation value, then the payoff to the median district in the state (and hence to the senator) is also equal to the continuation value. Hence, to get the support from the L senator a proposal must include a payoff equal to the continuation value to at least two districts in the $\mathrm{L}$ state.

${ }^{12}$ Notice that agents cannot directly select $q_{t}$ with their proposals. Agents can only select which coalitions to form, which in turn will determine the probability that members are included in the coalition. Let $q_{L L S}$ denote the probability that a coalition type LLS is offered. (The probability that a type LSS is formed is $\left.1-q_{L L S}.\right) \quad q_{S}$ and $q_{L}$ are given by: $q_{S}=\frac{1}{4}\left(1-q_{L L S}\right)+\frac{3}{4}\left(\left(1-q_{L L S}\right)+\frac{1}{2} q_{L L S}\right)$ and $q_{L}=$ $\frac{2}{4}\left(\frac{1}{3}\left(1-q_{L L S}\right)+\frac{2}{3} q_{L L S}\right)+\frac{2}{4} \frac{1}{2} q_{L L S}$. In equilibrium, $q_{S}=q_{L}=\frac{1}{2}\left(\right.$ and $\left.v_{S}=v_{L}\right)$ with $q_{L L S}=\frac{4}{5}$.

${ }^{13}$ The L senator is the proposer with probability $\frac{1}{3}$ and in a MWC she will include two L districts. Hence, the probability that any L district receives the proposer's share is $\frac{2}{9}$.

${ }^{14}$ Assume that $v_{S}>v_{L}$. Then, a proposer would like to include as many L districts as possible in the MWC -only LLS coalition types will be formed. The continuation values are given by: $v_{S}=\frac{1}{3}\left(1-2 v_{L}\right)+\frac{1}{3} \frac{1}{2} v_{S}$
} 


\subsection{Weighted Voting Experiment}

This institution involves a unicameral setting with one member per state and malapportioned votes. Let $w_{S}$ and $w_{L}$ represent the votes assigned to an $\mathrm{S}$ and an $\mathrm{L}$ member, respectively. The total number of votes is $w=2 w_{S}+w_{L}$. I set $w_{S}=1$, so that there is one vote per unit of population in $\mathrm{S}$ states. The $\mathrm{L}$ state is awarded more votes, but voting power is malapportioned if the voting weight $\left(\frac{w_{L}}{w}\right)$ is lower than the population weight $\left(\frac{3}{5}\right)$. I set $w_{L}=2$, which means that $w=4$, and that the voting weight of $\mathrm{L}\left(\frac{2}{4}\right)$ doubles the one for $S\left(\frac{1}{4}\right) \cdot 15$

As explained in detail in STA, weighted voting introduces a technical complication. In the parametrization, a simple majority of at least $\frac{w}{2}+1=3$ votes is required for a proposal to pass. But this means that any MWC must include the L state. Theoretically, this problem can be dealt with by replicating voting games: study the equilibria of games in which the number of players of each type is multiplied by $r \in \mathbb{Z}^{+}$. A game with $r$ replications involves a total of $r m$ committee members and a simple majority out of $r w$ total votes is needed for a proposal to pass. I set $r=2$ and, thus, the weighted voting experiment will have a total of six states $(r m=6)$ : four $\mathrm{S}$ and two $\mathrm{L}$, for an underlying total population of $r n=10$ and a total of $r w=8$ votes.

A proposal is a 6 -dimensional vector that indicates how the budget is shared between the six states. A member of type $t$ will be recognized as the proposer with probability $p_{t}$, which determines how proposal power is allocated and is the main treatment variable. Proposal power is evenly apportioned if the recognition probabilities are equal to the state's population weight. In the parametrization, this means that an $\mathrm{L}$ state, which triples an $\mathrm{S}$ state in population size, is three times more likely than an $\mathrm{S}$ state to be the proposer. Meanwhile, proposal power is malapportioned if the recognition probabilities are equal to the voting weights. In that case, the small-state advantage in terms of voting weights is also present at the proposal stage. Finally, the weighted voting institution presents a very natural case of extreme malapportionment: when all states are equally likely to be selected as proposers.

\section{Theoretical predictions}

The main prediction for this experiment is that regardless of how proposal power is allocated, there is an advantage for $\mathrm{S}$ states in terms of resources per capita.

and $v_{L}=\frac{2}{9} \frac{1-v_{S}}{2}+\frac{2}{3} \frac{2}{3} v_{L}$-notice that $q_{S}=\frac{1}{2}$ and $q_{L}=\frac{2}{3}$. Solving for $v_{S}$ and $v_{L}$ leads to the shares reported in Result 2, that are consistent with the assumption $v_{S}>v_{L}$. For a more general finding, see AST Prop. 4.

${ }^{15}$ This feature is also consistent with the parametrization for the bicameralism experiment. Adding votes in the house and the senate, there is a total of 8 votes: 4 allocated to the L state and 2 to each $\mathrm{S}$ state. 
Result 3. If proposal power is evenly apportioned, malapportioned or extremely malapportioned, then at any SSSPE the continuation value per vote is independent of state size.

The result holds for the parametrization in the experiment, but it is a special case of more general results: see STA Proposition 3 (proposal power malapportioned) and Proposition 4 (proposal power extremely malapportioned), and Online Appendix A for a proof of the evenly apportioned case. To develop some intuition notice first that a member will vote in favor of a proposal that allocates to their state an amount at least as high as their continuation value, $y_{t}=p_{t}\left(1-\underline{y}_{t}\right)+\left(1-p_{t}\right) q_{t} y_{t} \cdot{ }^{16}$ Solving for $q_{t}$ :

$$
q_{t}=\frac{y_{t}-p_{t}\left(1-\underline{y}_{t}\right)}{\left(1-p_{t}\right) y_{t}}
$$

Result 3 implies that $y_{t}$ (and thus $\underline{y}_{t}$-the amount allocated to non-proposers) takes on the same value regardless of $p_{t}$. Equation (1) shows that $q_{t}$ and $p_{t}$ are negatively related. Consider the case of an L state. A move from proposal power being malapportioned to being evenly apportioned involves an increase in $p_{t}$ for that state. Other things equal, that state's continuation value should go up. In turn, a higher continuation value makes the state more expensive to invite into the coalition. Thus, proposers would include them less often ( $q_{t}$ decreases) and there is a decrease in their continuation value. The process stops when there is no difference in relative prices, an event that happens when the continuation value equals what the state can actually deliver to the proposer (their voting weight). Hence, in equilibrium, the continuation value equals the voting weights: $y_{t}=\frac{w_{t}}{r w}$, which means that the continuation value per vote $\left(z_{t}\right)$ is independent of $t: z=z_{t}=\frac{y_{t}}{w_{t}}=\frac{1}{r w}$.

\section{Experimental treatments}

The weighted voting experiment will involve three treatments, depending on how proposal power is allocated. In the 'Extremely malapportioned' treatment ( $W V$ Extremely Malap) all members are selected with equal probability $\left(p_{S}=p_{L}=\frac{1}{r m}=\frac{1}{6}\right)$. In the 'Malapportioned treatment' ( $W V$ Malap $)$ probabilities are equal to the voting weights $\left(p_{S}=\frac{w_{S}}{r w}=\frac{1}{8}\right.$; $\left.p_{L}=\frac{w_{L}}{r w}=\frac{2}{8}\right)$. In principle, the third treatment would have recognition probabilities proportional to population: $1 / 10$ for $\mathrm{S}$ and $3 / 10$ for $\mathrm{L}$ states. However, notice that these probabilities are quite close to those in $W V$ Malap: $0.125 \mathrm{v} 0.1$ for $\mathrm{S}$ and $0.25 \mathrm{v} 0.3$ for $\mathrm{L}$ states. These small differences are likely to bias in favor of not finding a treatment effect, which is what the theory predicts. In order to stress test the model, the 'Near evenly apportioned' treatment ( $W V$ Near Even) is a more extreme version with recognition probabilities

\footnotetext{
${ }^{16}$ The continuation values $y_{t}$ is measured at the state level. The measure used for bicameralism, $v_{t}$, is in per-capita terms. In other words: $v_{t}=\frac{y_{t}}{\text { Population }_{t}}$.
} 
at 0.05 and 0.4 for $\mathrm{S}$ and $\mathrm{L}$ states respectively. In this treatment it no longer holds that the allocation of resources is determined by voting weights. ${ }^{17}$ These three treatments cover a wide range of recognition probabilities. ${ }^{18}$

\subsection{Summary and Implementation Details}

The most relevant quantitative predictions are summarized in Table 2 and the main goal of the experimental design is to test two hypotheses.

Bicameralism Hypothesis: The allocation of proposal power influences the allocation of resources. When proposal power is malapportioned, the allocation of resources favors $\mathrm{S}$ states. If proposal power is evenly apportioned, no state is favored.

Weighted Voting Hypothesis: In treatments that do not involve extreme recognition probabilities for L states ( $W V$ Malap and WV Ext Malap), the allocation of proposal power does not influence the per-capita allocation of resources, which favors $\mathrm{S}$ states.

Each session consisted of 15 repetitions of the task, and I will refer to each repetition as a round. In each round members are randomly allocated into new committees, and a round is over when a proposal is accepted. ${ }^{19}$ In the bicameralism experiments, a total of 16 subjects participated in each session so that it is possible to accommodate two 8-member legislatures. At the beginning of each session 10 subjects were assigned the role of representatives and 6 the role of senators. Since the tasks are different, in order to facilitate learning, the role was

\footnotetext{
${ }^{17}$ To see why, notice that if $y_{t}=w_{t} /(r w)$, then using (1) $q_{L}=0$. This means that for the resources to be distributed according to voting weights, members need to never include L states in the coalition when they are not proposing. But this is clearly impossible since an $\mathrm{S}$ proposer always needs an $\mathrm{L}$ member to achieve a simple majority of the votes. In the SSSPE, the large recognition probabilities will give L state members an advantage, and thus: $y_{L}>2 y_{S}$. This, in turn, implies that L-members will be offered to be in the coalition as little as possible. Eventually, $y_{S}=1 / 12, y_{L}=1 / 3$. Notice that while this treatment is useful as a testing device, it may be very difficult to implementat outside of the laboratory. While the population weight of $\mathrm{L}$ is 3 times that of $\mathrm{S}$, in this treatment an $\mathrm{L}$ state is 8 times more likely to be selected as a proposer.

${ }^{18}$ There is also a wide range in the predictions for $q_{t}$ across treatments. Let $q_{L L S}$ denote the probability that a coalition type LLS is offered. (The probability that a type LSSS is formed is $1-q_{L L S}$ ) In WV Near Even only LSSS coalitions will be offered given that L members are more expensive than S members $\left(q_{L L S}=0\right)$. This leads to $q_{S}=\frac{7}{10}$ and $q_{L}=\frac{1}{10}$. For other treatments it is possible to compute $q_{S}$ and $q_{L}$ using Result 3 and (1), leading to $q_{S}=\frac{4}{7}$ and $q_{L}=\frac{1}{2}\left(q_{S}=\frac{2}{5}\right.$ and $\left.q_{L}=\frac{7}{10}\right)$ in $W V$ Malap (WV Ext Malap). To compute the probabilities that certain coalition types are formed, let $\tilde{p}_{t}$ denote the probability that the proposer is of a state $t$ when the member for which $q_{t}$ is being computed is not the proposer. Then, $q_{S}$ and $q_{L}$ are given by: $q_{S}=\tilde{p}_{S}\left(\frac{2}{3}\left(1-q_{L L S}\right)\right)+\left(1-\tilde{p}_{S}\right)\left(\frac{1}{4} q_{L L S}+\frac{3}{4}\left(1-q_{L L S}\right)\right)$ and $q_{L}=\tilde{p}_{L} q_{L L S}+\left(1-\tilde{p}_{L}\right)\left(q_{L L S}+\frac{1}{2}\left(1-q_{L L S}\right)\right)$. I get: $q_{L L S}=\frac{1}{4}$ in $W V$ Malap and $q_{L L S}=\frac{1}{2}$ in $W V$ Ext Malap.

${ }^{19}$ Because subjects are randomly re-matched after each round there is only one independent observation per session.
} 

the weighted voting experiment, 12 or 18 subjects were randomly assigned into committees of 6 to distribute $\$ 80 .^{22}$

Three sessions for each treatment in both experiments were conducted at New York University's Center for Experimental Social Science, recruiting subjects from the student population. A total of 96 and 120 subjects participated in the bicameralism and weighted voting sessions, respectively. A session lasted for approximately 80 minutes and subjects received on average $\$ 25$. Payment consisted on a $\$ 15$ show-up fee plus the earnings in one randomly selected round. ${ }^{23}$

\section{Results}

\subsection{Main Result}

This section shows that the data are qualitatively in line with the hypotheses presented above. At the same time, the analysis identifies quantitative differences relative to the predictions, and the next two sections explore in detail the sources of such discrepancies.

A brief summary of the data is presented in Table 3 that shows average allocations by state size and treatment. Within each treatment the main question is if there is a difference depending on the state size, which will be captured by comparing across columns. Between treatments the comparison is in the allocation of proposal power for each institution. To compute the figures, the unit of observation is each proposal and I use all submitted proposals

\footnotetext{
${ }^{20}$ The house and the senate were referred to as Group 1 and 2 and the states were referred to as regions and identified with colors. Colors were reassigned in each new round. The interface worked in two steps to help understanding the mapping from proposals to payoffs. First, subjects introduced their decisions on how to distribute $\$ 50$ among the 5 districts. Before a proposal was submitted, subjects were asked to check the payoffs that such allocation implied for each member of the legislature, and their own payoff was highlighted. After learning the implied payoffs subjects could change their decisions as many times as they wanted before submitting their proposals. Their screens also displayed the whole history of play, namely, proposals submitted to voting and the voting decisions of each member. Details in Online Appendix C.

${ }^{21}$ Actual expenditures per legislature in the laboratory are higher than $\$ 50$. For example, the equal division of the budget involves a payment of $\$ 10$ to each house member and $\$ 10$ to each senator for a total of $\$ 80$. In the SSSPE with evenly apportioned proposal power, the expected payoff to each participant is $\$ 10$.

${ }^{22}$ The instructions are available in Online Appendix C. At the beginning of the section subjects are assigned to one of two roles: a block that controls 1 vote or a block that controls 2 votes. The role is fixed throughout the session, but in each round subjects are randomly matched into a new committee of 6 . Subjects who control two votes are paid the allocation they received times $1 / 2$. The reason for this is to control for incentives to punish or reward a member based on the votes they were exogenously allocated. Instead, the payment setup allows to focus on the effect of changing recognition probabilities. From a theoretical point of view it does not make a difference if payoffs are multiplied by a constant. With this adjustment, a budget of $\$ 80$ implies an expected payoff of $\$ 10$ for each participant.

${ }^{23}$ The interface was designed using z-Tree, Fischbacher (2007). If in the round selected for payment a subject was allocated $\$ 0$, there would be no payoff on top of the show-up fee.
} 

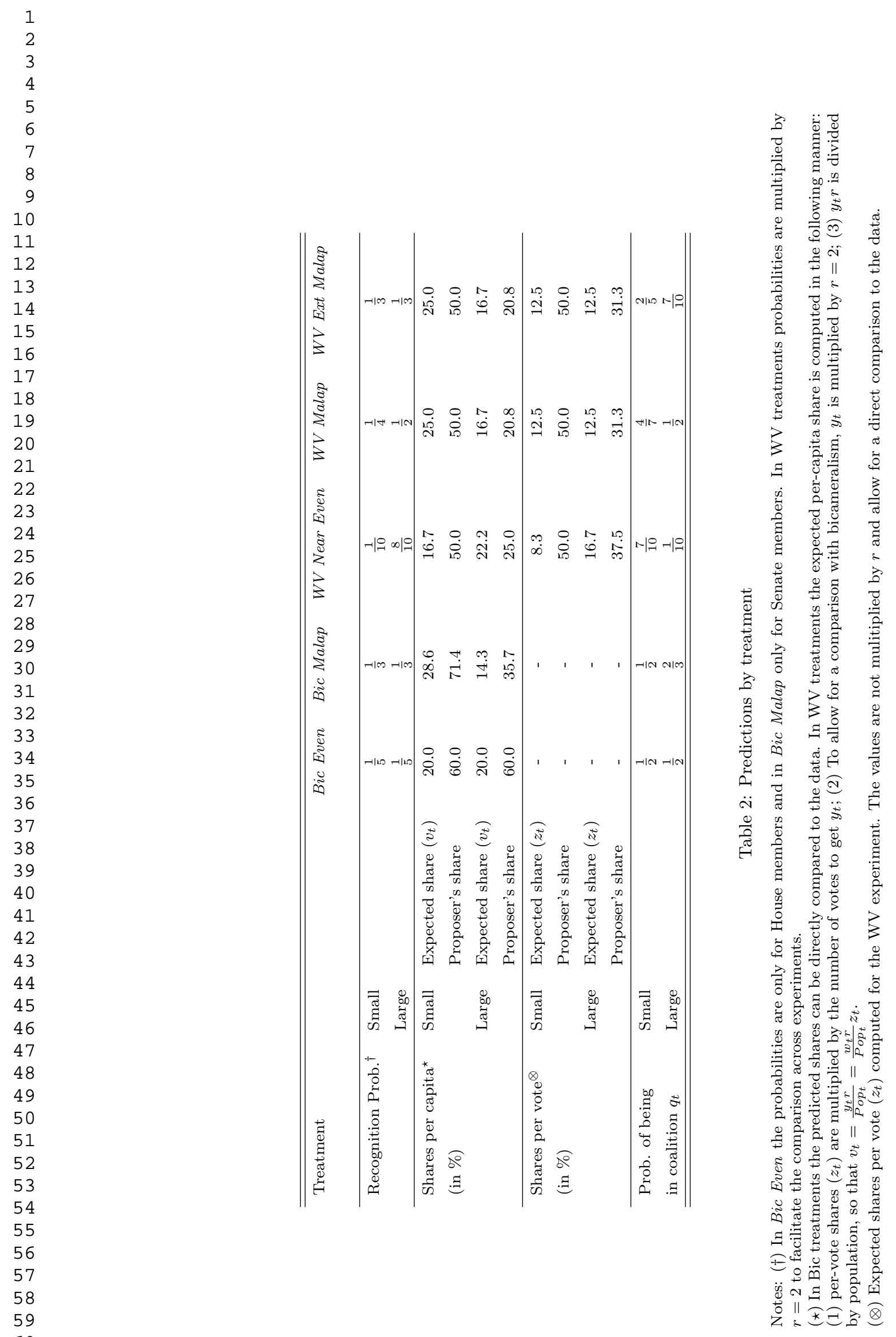
Table 3: Observed average allocations (in \%)

Notes: (1) Theoretical predictions between parentheses. (2) See footnote 26 for a description of the statistical test to determine statistical significance of the difference reported in the last column. $(*),(* *),(* * *)$ indicate significance at the 10,5 and $1 \%$ level respectively.

(before one is selected to be voted on). ${ }^{24}$ For each proposal I compute the average allocated to $\mathrm{S}$ and L districts, obtaining a distribution of proposals by district size. Columns (a) and (b) of the table report the means of these distributions. For the bicameral experiment, reported allocations are measured in units per capita, which can be contrasted to the theoretical prediction on $v_{t}$. For weighted voting treatments I present both: averages per vote -that can be contrasted to $z_{t^{-}}$and per capita to facilitate the comparison with bicameralism. ${ }^{25}$

\section{Bicameralism}

In the case of bicameralism, averages are qualitatively close to the theoretical predictions. When the proposer is selected in the house (Bic Even) there is a two percent difference in favor of $\mathrm{S}$ districts, which is relatively small but statistically significant. ${ }^{26}$ If the proposer is

\footnotetext{
${ }^{24}$ Qualitatively, the main findings hold if I only use proposals that pass. In fact, the distribution of proposals that were voted on and proposals that were not selected for a vote look alike. For each treatment and state size, I use a Kolmogorov-Smirnov test where the null is that the samples for both distributions come from the same underlying distribution. In all cases I cannot accept the null at standard significance levels.

${ }^{25}$ Per-vote proposals are multiplied by $w_{t}$ and $r=2$, and then divided by the corresponding state's population. To compute averages, submitted proposals are weighted by the probability with which they would be selected in each treatment.

${ }^{26}$ In order to test for statistical significance within each treatment, I construct for each proposal a variable Difference, which is equal to the average allocation to an $\mathrm{S}$ district minus the average allocation to an $\mathrm{L}$ district. A positive difference signals an S per-capita advantage. I treat the dataset as a panel and regress Difference on a constant. For the weighted voting treatments submitted proposals are weighted by the probability of selection. To control for possible session effects, standard errors are clustered by session. Online Appendix B reports on similar regression analysis that also includes dummies for rounds within a session. Qualitatively, similar conclusions hold. In the text, I will claim that there is statistical significance if the corresponding hypothesis is rejected at least at the $5 \%$ level.
} 
selected from the senate (Bic Malap), the difference is higher at $6.1 \%$ and also statistically significant. This figure, however, is well below the 14 points difference predicted by the theory. Comparing across treatments, there is a four percent advantage for $\mathrm{S}$ districts that is statistically significant at the $1 \%$ level. $^{27}$

The finding that allocations favor $\mathrm{S}$ districts relatively more when the proposer is selected among senators is not only reflected on the averages, but on the full distribution as well. Figure 1 presents the cumulative distribution of allocations by bicameralism treatment and district size. Consider first the figure on the right side that presents the Bic Malap treatment. For both district sizes there are a few proposals with allocations close to zero, but as the allocated shares increase, the distribution for S (solid-blue) is below and to the right of the distribution for $\mathrm{L}$ (dashed-red). In other words, allocations for $\mathrm{L}$ districts are concentrated around lower shares, while allocations for $\mathrm{S}$ districts are more likely to involve higher shares. ${ }^{28}$ In fact, the distribution of $\mathrm{S}$ first order stochastically dominates (FOSD) L. ${ }^{29}$ Meanwhile, when the proposer is selected from the house -figure on the leftthe distributions cross each other four times and there is no statistical FOSD. The figure also shows that the two percent difference in favor of $\mathrm{S}$ reported in Table 3 is only driven by relatively high shares. I now summarize the main findings with respect to the bicameralism hypothesis.

Bicameralism Hypothesis: Consistent with the theory, there is evidence that the allocation of proposal power influences the allocation of resources. When proposal power is malapportioned, S states receive an extra share of the resources. Quantitatively, the average extra benefit for $\mathrm{S}$ states is smaller than predicted.

\section{Weighted Voting}

The last three rows of Table 3 show average per-vote allocations for $\mathrm{S}$ and L states in the the weighted voting experiment. On a per-vote basis there is an advantage for L states that is significant in all treatments, but relatively smaller -and close to the prediction- for treatments where the theory predicts no difference. To further scrutinize the finding on the mean, Figure 2 presents the cumulative distribution of per-vote allocations by state size and

\footnotetext{
${ }^{27}$ To test for statistical significance I proceed as described in footnote 26 , include in the analysis data from both treatments and add a treatment dummy on the right-hand side.

${ }^{28}$ For both distributions there is a mass point at 20 percent. In all treatments there are proposals that equally split the budget across the five districts, which imply allocations of 20 percent for $\mathrm{S}$ and L districts. A full breakdown of coalition types is presented in Table 8 of Online Appendix B.

${ }^{29}$ I test for first order stochastic dominance using the test in Barrett and Donald (2003). The test consists of two steps. I first test the null hypothesis that the L distribution either first order stochastically dominates or is equal to the $\mathrm{S}$ distribution. I reject this null hypothesis, the corresponding $p$-value is 0.00 . I then test the null hypothesis that the $\mathrm{S}$ distribution first order stochastically dominates the $\mathrm{L}$ distribution. I cannot reject the null in this case, with a corresponding $p$-value of 0.965 .
} 


\section{Bic Even}

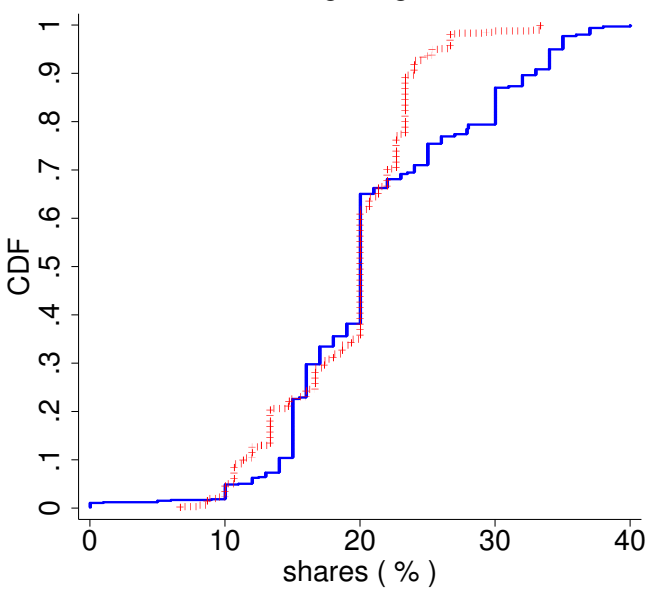

\section{Bic Malap}

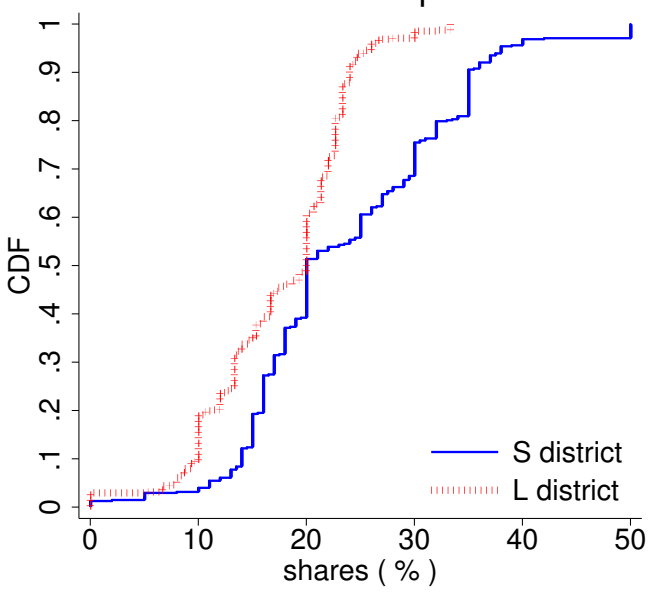

Figure 1: Bicameralism -Cumulative distribution of per-capita allocations by district size-

WV treatment. Notice first that the difference between the S and L distributions depends on the recognition probabilities. ${ }^{30}$ When L states are eight times more likely selected as proposers than S states ( $W V$ Near Even treatment), the per-vote allocation to L states FOSD that of S states (left-most figure). ${ }^{31}$ The same finding holds for WV Malap, but clearly the distributions are closer to each other (center figure). Finally, while there is a significant 2.2 percent difference that favors $\mathrm{L}$ states in mean allocations for the $W V$ Ext Malap treatment (Table 3), the distribution for L states no longer FOSD the S states counterpart.

To determine the effect of malapportionment, the question is if the advantage for $\mathrm{L}$ states in per-vote terms would be large enough to compensate for population. With this aim, Table 3 also shows allocations by WV treatment in per-capita terms. The signs of the differences in column (c) are consistent with the theory: there is a per-capita advantage for L states only in the $W V$ Near Even treatment, but quantitatively the differences are smaller than predicted in all cases. ${ }^{32}$ I finally summarize the findings relative to the hypothesis.

Weighted Voting Hypothesis: In treatments where the per-vote allocations are predicted

\footnotetext{
${ }^{30}$ For WV treatments, the equal split of the budget allocates $\frac{1}{8}$ per vote. In all treatments there is a mass at the $12.5 \%$ mark, indicating a presence of such allocations. Table 10 in Online Appendix B presents a detailed breakdown of coalition types.

${ }^{31}$ Using the test of Barrett and Donald (2003), the null hypothesis that the L distribution either first order stochastically dominates or is equal to the $\mathrm{S}$ distribution cannot be rejected $p$-value is 0.864 . The null hypothesis that the $\mathrm{S}$ distribution first order stochastically dominates the L distribution is rejected ( $p$-value of 0.000). The corresponding p-values for the $W V$ Malap treatment are 0.860 and 0.000 .

${ }^{32}$ As a reference, the per-capita counterpart to Figure 2 is presented in Online Appendix B (Figure 5).
} 
WV Near Even

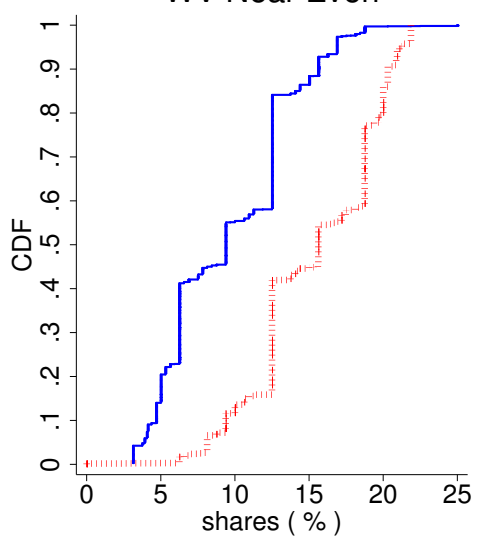

WV Malap

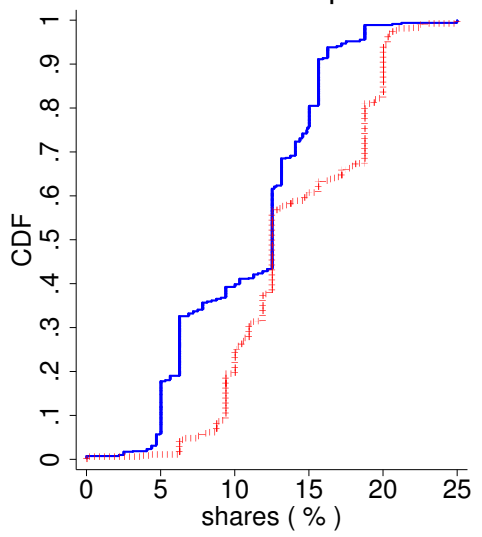

WV Ext Malap

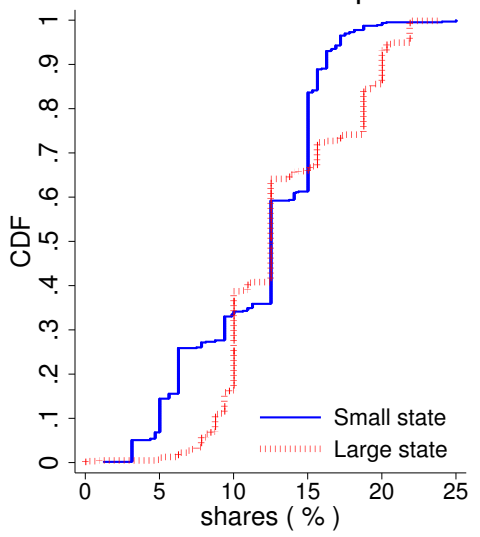

Figure 2: Weighted Voting -Cumulative distribution of per-vote allocations by state size-

to be equal across state sizes ( $W V$ Malap, $W V$ Ext Malap) I find a small difference that favors $\mathrm{L}$ states. In per-capita terms, the advantage for $\mathrm{L}$ states is not enough to compensate for population and there is a significant advantage for $\mathrm{S}$ states that is qualitatively in line with the theory, but quantitatively smaller than predicted. When the probability of recognizing an L state is $80 \%$ ( $W V$ Near Even), there is a higher per-vote difference for L states that also holds in per-capita terms but is smaller than predicted.

\subsection{Decomposing Proposals}

As the computation of theoretical continuation values shows, expected allocations depend on both: actual allocations and the likelihood that such allocations are offered. From a theoretical perspective, actual allocations depend on whether the member is selected as a proposer, included in the coalition as a non-proposer, or excluded from the coalition. The likelihood that allocations are offered depends on the exogenous recognition probabilities, and on the coalitions that proposers endogenously form, as captured by $q_{t}$. All of these forces combined play a role in the main results previously reported. In this section, I study how each one influences final outcomes.

\section{Bicameralism}

A basic prediction of the theory is that proposals should involve MWC. In the Bic Even and Bic Malap treatments a majority of proposals (60 and 58 percent, respectively) do satisfy the definition. ${ }^{33}$ Since proposing a MWC is a necessary condition for the theoretical

\footnotetext{
${ }^{33}$ A full breakdown of proposed coalitions is presented in Table 8 of Online Appendix B. As is standard in the literature (see, for example, Fréchette et al. 2003), I define MWC as proposals in which excluded
} 

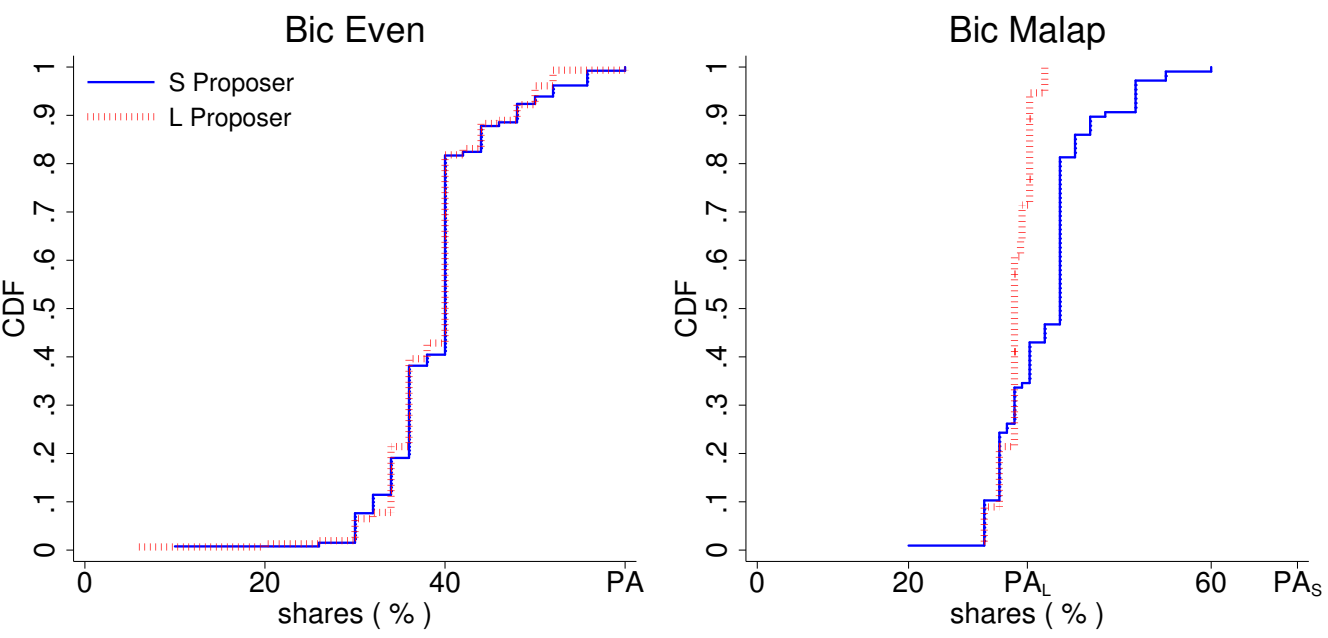

Figure 3: Proposer Allocations in Bicameralism Experiments

Notes: (1) PA: Predicted Proposer Allocation. (2) In Bic Even PA does not depend on state size. In this case PA=60. (3) In Bic Malap allocations depend on state size, which is indicted with a sub-index. $\mathrm{PA}_{S}=71.4, \mathrm{PA}_{L}=35.7$.

predictions, I first focus on such proposals. ${ }^{34}$

For proposals that involve MWC, I compute the distribution of allocations to the proposer and to non-proposers by district size. The cumulative distributions for proposer allocations by district size are presented separately for each treatment in Figure 3. Consider first the Bic Even treatment on the left panel: distributions largely overlap, there is no statistical difference in means and, in fact, the distributions are quite centered around the mean. ${ }^{35}$ There is also no difference across state sizes in the distributions for non-proposer

members receive ten percent of the budget or less. If I consider subjects who are assigned ten percent of the budget or less, $94 \%$ and $97 \%$ of them reject such proposal in the bicameralism and weighted voting experiments, respectively. Moreover, in the unusual cases when subjects voted in favor their positive vote would not change the outcome in more than $85 \%$ of the cases. In a few words, it seems reasonable to assume that a proposer who allocates ten percent of the budget or less to a coalition partner is not expecting that member to vote in favor.

${ }^{34}$ Besides MWC, the theory also predicts that proposals will be accepted in stage 1 . A majority of proposals are indeed accepted in stage 1. The figures for Bic Even and Bic Malap are than 76 and 59 percent respectively. Not observing convergence towards $100 \%$ was expected given that there is no discounting in this game. Indeed, previous experimental evidence on unicameral legislatures (Fréchette et al. (2005a)) has documented similar early acceptance rates in cases with no discounting, while convergence towards $100 \%$ stage 1 acceptance probability is more likely as the discount rate increases.

${ }^{35}$ From now on all statistical statements on the mean result from a random effects panel data regression in which rounds capture the time dimension and subject id represents the longitudinal dimension. The unit of observation is the proposal for the last stage of each round. The quantity of interest is on the left-hand side (e.g. Allocation to non-proposers in the Bic Even treatment). The right-hand side involves a constant and the variable being tested (e.g. a dummy that takes value 1 if the district of the proposer is small). Standard errors are clustered by session. 
Table 4: Bicameral Experiment -Computing Expected Payoff for MWC proposals-

Notes: (1) $E_{t}=p_{t} P A_{t}+\tilde{p}_{t} q_{t} N P A_{t} . \tilde{p}_{t}$ is the probability that the member is not the proposer. In all treatments $\tilde{p}_{t}=1-p_{t}$, except in Bic Malap when computing $E_{L}$, where $\tilde{p}_{L}=\frac{2}{3}$. (2) Theoretical predictions between parentheses. (3) See Online Appendix B for details on the calculations of $q_{t}$.

allocations, which are presented in Figure 6 of Online Appendix B. ${ }^{36}$

The mean allocations for proposers and non-proposers are presented in Table 4, with theoretical predictions between parentheses. Qualitatively, the ordering of proposer's and non-proposer's allocations in Bic Even is in line with the theoretical predictions. Quantitatively, there are differences. On average, proposers keep almost $40 \%$ of the budget, but this value is significantly below the theoretical prediction. Non-proposers receive approximately $29 \%$ of the budget, which is significantly above the theoretical value.

When proposal power is malapportioned, it is also the case that the distributions of non-proposer allocations are almost identical, and the difference in means is not statistically significant. ${ }^{37}$ This finding is not in line with the theoretical prediction, according to which L non-proposers are offered a lower share given their lower theoretical continuation value. There is, however, a difference on proposer allocations depending on size (right panel of Figure 3), where the allocations for S proposers FOSD the L-state counterpart. ${ }^{38}$ While this is qualitatively in line with the theory, the difference in means is smaller than predicted. ${ }^{39}$

\footnotetext{
${ }^{36}$ Figure 6 in Online Appendix B also shows that the distribution of proposer allocations for either size FOSD the corresponding distribution of non-proposer allocations.

${ }^{37}$ For details, see Figure 6 of Online Appendix B.

${ }^{38}$ Using the test of Barrett and Donald (2003), the null hypothesis that the L distribution either first order stochastically dominates or is equal to the $\mathrm{S}$ distribution is rejected $p$-value is 0.000 . The null hypothesis that the $\mathrm{S}$ distribution first order stochastically dominates the $\mathrm{L}$ distribution is not rejected ( $p$-value of 0.965). The mean proposer allocation to the S-state senator is significantly different to that of a L-state senator at the $1 \%$ level.

${ }^{39}$ The observed S proposer allocation is significantly different than the theoretical prediction of claiming
} 
Comparing between treatments, there are no differences in non-proposer allocations and no differences in proposer allocations to $\mathrm{S}$ districts. The average proposer allocations to the L state are significantly lower when the proposer is selected in the senate than when it is selected in the house. In all cases, however, proposer allocations are below the predicted values and non-proposer allocations are above. ${ }^{40}$

The findings on allocations suggest that in expected terms: i) there is no difference between district sizes in Bic Even; and ii) there is an advantage for S districts when the proposer is selected from the senate. Yet, allocations are not the only determinant of expected payoffs. In the case of the Bic Even treatment, there would be no difference in expected payoffs if both district sizes are equally likely to be included in the coalition when they are not proposing $\left(q_{S}=q_{L}=1 / 2\right)$, which requires that LLS coalitions are formed with probability $80 \%$ (see footnote 12). Indeed, LLS coalitions are more likely than LSS ones, but the observed frequency at $62.8 \%$ is lower than predicted. ${ }^{41}$ This, in turn, means that $\mathrm{S}$ members are slightly more likely than L members to be in the coalition -with observed values at $\hat{q}_{S}=0.6$, and $\hat{q}_{L}=0.4$. Eventually, the expected payoff to $\mathrm{S}$ districts is 3.9 percentage points higher than that of L districts (last row of Table 4). ${ }^{42}$

When the proposer is selected from the senate, the theory predicts that only LLS coalitions would be offered because $\mathrm{L}$ members have lower continuation values. In fact, if coalitions were formed as predicted by the theory $\left(q_{S}=\frac{1}{2}, q_{L}=\frac{2}{3}\right)$, the advantage for $\mathrm{S}$ states would disappear and, instead, there would be a net gain of three percent in expected terms for L states. ${ }^{43}$ But in the data there is no reason to include L members as non-proposers as much as possible, given that non-proposer allocations do not significantly differ on state size. In fact, S members actually propose LLS and LSS coalitions with comparable likelihood. ${ }^{44}$ This means that L states are invited to the coalitions with a lower frequency than predicted by the theory $\left(\hat{q}_{L}=0.48\right)$. Taking all into account (last row of Table 4 ), there is a six percentage points advantage for $\mathrm{S}$ districts in expected terms.

$71.4 \%$ of the pie. In the case of $\mathrm{L}$, the observed value is not significantly different than the theory prediction of $35.7 \%$.

${ }^{40}$ Figure 7 in Online Appendix B presents the cumulative distributions of Figure 3, but with a different organization. Each panel fixes the district size and compares distributions across bicameralism treatments.

${ }^{41} \mathrm{~A}$ binomial test with the null hypothesis that LLS coalitions are observed with probability $80 \%$ is rejected.

${ }^{42}$ The details of these computations are presented in Online Appendix B, Table 7.

${ }^{43}$ Given the allocations, there is an advantage of four percentage points for S states in terms of proposer allocations. But if $\mathrm{L}$ members were invited to the coalition as often as predicted by the theory, they would enjoy the non-proposer payoff (which in the data does not differ by size) more often. The net result of these forces would lead to a three percent gain for L states.

${ }^{44}$ The figure is $44.1 \%$ and the null hypothesis of the likelihood being equal to $50 \%$ cannot be rejected (two-sided binomial test). L senators only get a payoff if they form an LLS coalition. The payoff to L senators is the second-highest allocation to the state, so if they form an LSS coalition their payoff would be zero. Indeed all senators in the data form LLS coalitions. Further detail in Online Appendix B, Table 4. 
As mentioned earlier in this section, approximately $60 \%$ of coalitions are minimum winning in both bicameralism treatments. To reconcile the findings in this section with the overall differences reported in the previous section it is necessary to study what happens with the remaining proposals. In the Bic Even treatment, $23 \%$ of all proposals involve a division that allocates at least ten percent of the budget to all members (and typically involves an equal split) and $14 \%$ of proposals involve four-member coalitions (either one $\mathrm{S}$ or one $\mathrm{L}$ district is excluded). For either of these coalition types there is almost no difference between average allocations to S and L states, so that when averaged with MWC the advantage for S districts is lower and closer to the two percentage points reported in the previous section. ${ }^{45}$

In the Bic Malap treatment, the most frequent coalition that is not minimum winning is LLSS (20\% of all proposals). Three-quarter of these proposals are offered by S senators and on average involve a ten percent advantage for $\mathrm{S}$ districts. There are also proposals that either allocate funds between S and L districts in a comparable manner (e.g. those that include a payoff of at least ten percent of the budget to all members) or that benefit L districts (e.g. coalitions of type LLLS). Taking into account all proposals that do not involve a MWC I also find an advantage for S states close to six percentage points. Hence, once averaged with MWC the overall advantage reported for S states is consistent with the aggregate figure reported in the previous section.

I now summarize the main findings for the bicameralism experiment.

Finding 1 (Bicameralism) (a) When proposal power is malapportioned, the distribution of proposer allocations for S districts FOSD that of L districts. (b) There is no difference in proposer allocations across state sizes when proposal power is evenly apportioned. (c) There is no difference between proposer allocations in the Bic Even treatment and S proposer allocations in the Bic Malap treatment. (d) Proposer allocations FOSD non-proposer allocations. (e) There is no difference between non-proposer allocations across treatments or across state sizes. (f) In both treatments, $\mathrm{S}$ districts are included in the coalition more often than predicted by the theory.

\section{Weighted Voting}

Focusing on proposals that satisfy MWC, Figure 4 presents the cumulative distribution of per-vote allocations for proposers by treatment and state size. ${ }^{46}$ Table 5 provides a summary of corresponding averages for proposers and non-proposers.

Several patterns are common to all treatments. First, proposer allocations are signifi-

\footnotetext{
${ }^{45}$ Detailed computations are provided in Online Appendix B, Table 8.

${ }^{46}$ The full breakdown of coalition types is presented in Online Appendix B, Table 10. Approximately sixty percent of all coalitions are minimum winning. More than seventy percent of proposals in all treatments are accepted in the first stage.
} 

cations depending on state size is not significant and the distributions largely overlap (see Figure 10 in Online Appendix B). Third, as Figure 4 illustrates, a similar finding holds for proposer allocations: the difference between $\mathrm{S}$ and $\mathrm{L}$ states is not significant in any treatment.

There are only small differences comparing allocations between treatments. ${ }^{48}$ There are no significant differences in non-proposer allocations in any pair-wise comparison of treatments. The only significant difference is that the proposer's allocation for $\mathrm{S}$ states is higher in $W V$ Near Even than in WV Ext Malap.

Expected payoffs also depend on recognition probabilities and the type of proposed coalitions. Table 5 provides information on the observed likelihood of being in the coalition when the subject is not the proposer $\left(q_{t}\right)$. In theory, as $p_{t}$ increases $q_{t}$ should decrease to keep the continuation value constant across the $W V$ Malap and $W V$ Ext Malap treatments for states of the same size. However, this is not verified in the data. Values of $q_{t}$ by state size are quite close across treatments, with the observed $q_{S}$ below $q_{L}$. The computation of the expected payoff is presented in the last set of rows of Table 5. There is an advantage of 8.9, 3.4 and 2.1 percentage points in per-vote allocations for L states in $W V$ Near Even, WV Malap and WV Ext Malap, respectively.

Approximately forty percent of all proposals do not satisfy the MWC definition and a detailed breakdown of coalition types by treatment is presented in Online Appendix B (Table 10). A common coalition type across treatments involves a proposal that allocates a per-vote share of at least ten percent to all members of the committee, and most frequently involves an equal split. The average per-vote allocation in proposals with coalitions that are not minimum winning involves a $0.6,1.3$ and 2.0 percentage-points advantage for L states in $W V$ Near Even, $W V$ Malap and $W V$ Ext Malap, respectively. Taking the weighted average by treatment leads to overall per-vote differences in line with Table 3.

Next I summarize the main findings of this section.

Finding 2 (Weighted Voting) (a) Within each treatment, per-vote proposer allocations do not differ depending on state size. (b) A similar finding holds for non-proposer allocations, which also do not differ between treatments. (c) Proposers take less than predicted by the theory and non-proposers receive more than predicted. (d) There is no endogenous response to changes in recognition probabilities: The probability that a member is included

\footnotetext{
${ }^{47}$ Figure 10 in Online Appendix B also includes the distributions non-proposer allocations. For each size, the distribution of proposer per-vote allocations FOSD that of non-proposers (using the test of Barrett and Donald (2003)).

${ }^{48}$ Figure 11 in Online Appendix B allows for an easier visual comparison of cumulative distributions between treatments.
} 

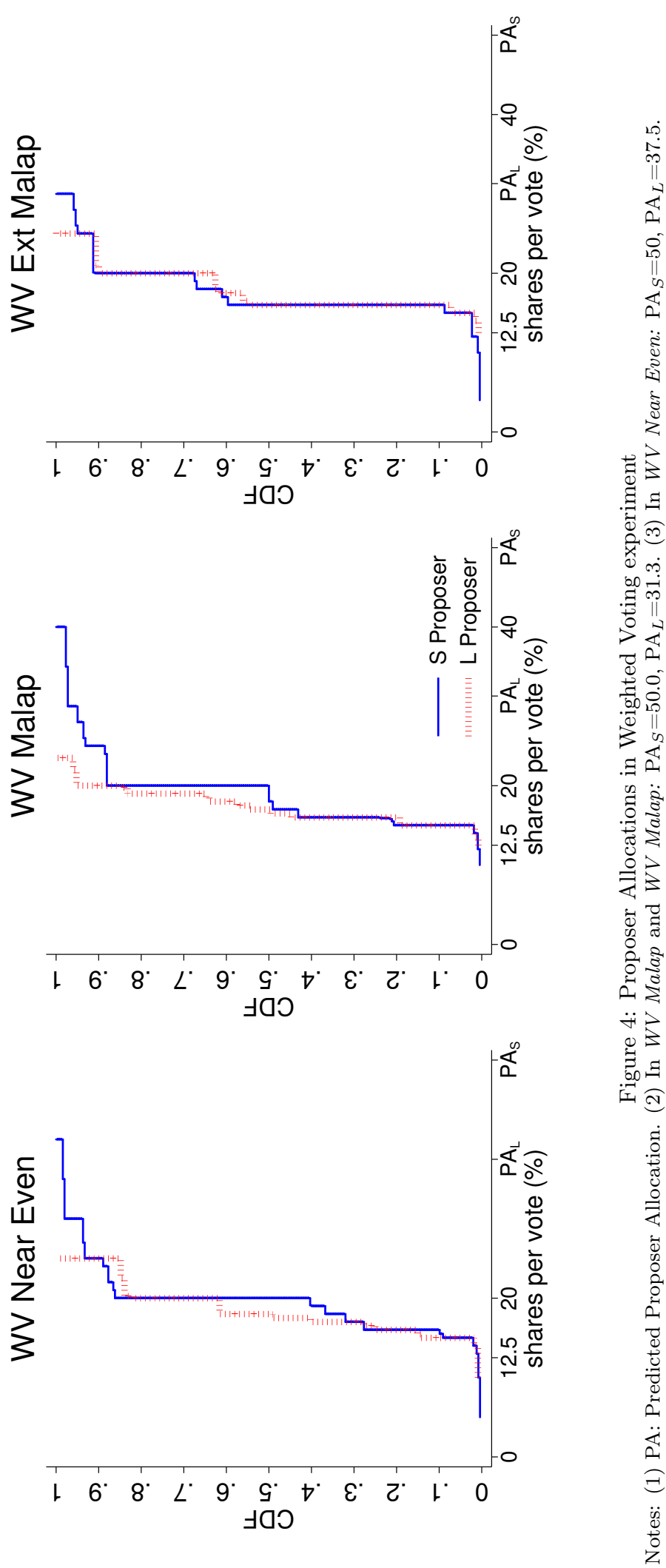

60

61 


\begin{tabular}{llccc}
\hline \hline & Acronym & Near Prop & Malap & Ext Malap \\
\hline Recognition probabilities & Small: $p_{S}$ & $\frac{1}{20}$ & $\frac{1}{8}$ & $\frac{1}{6}$ \\
& Large: $p_{L}$ & $\frac{8}{20}$ & $\frac{2}{8}$ & $\frac{1}{6}$ \\
\hline Proposer Allocation & Small: $P A_{S}$ & $24.1(50.0)$ & $24.0(50.0)$ & $22.8(50.0)$ \\
(\% of $P$ per vote) & Large: $P A_{L}$ & $22.9(37.5)$ & $21.8(31.3)$ & $22.9(31.3)$ \\
Non-proposer Allocation & Small: $N P A_{S}$ & $17.5(8.30)$ & $18.7(12.5)$ & $18.6(12.5)$ \\
(\% of $P$ per vote) & Large: $N P A_{L}$ & $18.3(16.7)$ & $18.7(12.5)$ & $18.6(12.5)$ \\
\hline Prob. of being in coalition & Small: $q_{S}$ & $0.34(0.70)$ & $0.42(0.57)$ & $0.37(0.40)$ \\
when not the proposer & Large: $q_{L}$ & $0.79(0.10)$ & $0.68(0.50)$ & $0.73(0.70)$ \\
\hline Expected payoff $(\%$ of $P$ per vote) $)$ & Small: $E_{S}$ & $7.90(8.30)$ & $10.7(12.5)$ & $11.3(12.5)$ \\
$E_{t}=p_{t} P A_{t}+\left(1-p_{t}\right) q_{t} N P A_{t}$ & Large: $E_{L}$ & $16.8(16.7)$ & $14.1(12.5)$ & $13.4(12.5)$ \\
\hline \hline
\end{tabular}

Table 5: Weighted Voting Experiment -Computing Expected Payoff for MWC proposalsNotes: (1) Theoretical predictions between parentheses. (2) See Online Appendix B (Table 9) for details on the calculations of $q_{t}$.

in the winning coalition when she is not the proposer does not adjust as predicted by the theory. (e) Expected allocations before the identity of the proposer is revealed are similar in the $W V$ Malap and $W V$ Ext Malap treatments. (f) Expected allocations for S states in the $W V$ Near Even treatment are lower than in other treatments; the opposite occurs for L states.

\section{Discussion}

While the data are qualitatively in line with the main hypothesis, there are departures from the predictions. From a theoretical point of view, one natural question is to what extent the solution concept (SSSPE) can organize the data. ${ }^{49}$ From the view point of malapportionment institutions, the finding indicates that proposal power can be used in bicameralism to reduce the small-state bias but the quantitative effect is lower than predicted. Since reform can be costly, a related question is how large is the actual welfare gain relative to the

\footnotetext{
${ }^{49}$ The theoretical environment studied in this paper intends to capture the behavior of politicians, while the experiment is conducted using college students. It seems reasonable to expect that professional politicians would offer proposals that satisfy some minimum level of rationality. If so, it is particularly useful to focus on proposals that satisfy MWC, which are the central object of study in section 3.2. Still, it is possible that within proposals that satisfy MWC the behavior of professionals differs from that of students. Of studies that compare the behavior of professionals and students that I know of, Siegel and Harnett (1964) is the closest to the experiment in this paper. In their experiment the central tension is the same as in most bilateral bargaining experiments, and they compare the behavior of college students with that of General Electric employees working in the Industrial Sales Operation division. In bilateral bargaining games (Roth 1995) it is frequent to observe divisions of the pie that are closer to being equal than it is predicted. Overall, they find that results of professionals are in line with results for students. For a broader comparison between the behavior of professionals and students see Fréchette (2015).
} 
prediction. In this section I discuss these two questions.

\section{Stationary Symmetric Sub-game Perfect Equilibrium}

Several of the properties required by the SSSPE are satisfied in the data. First, there is support for the notion of stationarity. There would be evidence against stationarity, for example, if the distribution of proposals depended on the stage of negotiation. Or, if proposals in stage 2 were to punish stage 1 proposers whose proposals were rejected. However, there is no evidence of such systematic punishments, and the distribution of stage 1 proposals is virtually identical to the distribution of proposals in later stages in all treatments. ${ }^{50}$

Second, sub-game perfection requires agents to be aware of possible future stages of negotiation when deciding whether to vote in favor or against a proposal. Theoretically, an agent should vote in favor when offered at least the continuation value. This indicates that agents should condition their vote on the amounts they are offered and not, for example, on how much the proposer keeps to herself. The analysis of voting behavior indeed is in line with prediction. ${ }^{51}$

Moreover, a majority of proposals involve MWCs and pass in the first stage without further delay; two properties required by the SSSPE. Focusing on proposals that satisfy MWC, there is a relatively low level of heterogeneity. Figures 6 and 10 in Online Appendix $\mathrm{B}$ show that non-proposer allocations and proposer allocations are heavily centered around their respective means in all treatments. While this evidence does not suggest that multiple equilibria could better organize the data, mean allocations (for proposers and non-proposers) are not centered around the unique outcome predicted by the SSSPE either. This departure, which has already been reported in the literature (e.g. Fréchette et al. 2003), entails that proposers take significantly less than predicted and that non-proposers, in turn, receive more than the equilibrium continuation value.

Finally, the evidence also supports the assumption of symmetry. There is no indication that proposers treat two non-proposers representing a state of the same size differently. In fact, there is more symmetry in allocations than predicted. In all treatments non-proposers from S or L states are offered a similar share regardless of how proposal power is allocated. In other words, while in some cases the theory predicts an asymmetry in continuation values

\footnotetext{
${ }^{50}$ Figures 9 and 13 in Online Appendix B show, the distribution of proposals in stage 1 and in stages after 1. To test for possible punishments I construct two variables. First, for all stage 1 proposals that were not selected to be voted on I keep track of the amount allocated to the subject whose proposal was selected. Second, I focus on all cases where the negotiation reached a second stage and keep track of the amount allocated to the subject who was the proposer in stage 1. Finally, I compute the difference between the first and the second variable: a positive difference would be evidence consistent with some type of punishment. A regression of the difference on a constant returns an estimate for the constant that is not significantly different from zero in all treatments.

${ }^{51}$ See Table 11 in Online Appendix B.
} 
across state sizes, in the data non-proposers are largely offered the same share regardless of the size of their states.

In the SSSPE, the expected payoff and the minimum payoff that would make a nonproposer vote favorably are equal to the equilibrium continuation value. In the data, however, the expected payoff and the payoff to non-proposers do not coincide (see Tables 4 and 5). As described in the previous paragraph, a clear pattern of behavior that deviates from the prediction is that non-proposer allocations do not differ in any meaningful way depending on state size. Other things equal, a state with an exogenous advantage in terms of recognition probabilities will have a higher expected share. But while in theory this should make such state more demanding when they are non-proposers, in the data this is not verified. Moreover, as all non-proposers receive an equal payment, there is no need to invite those with higher recognition probabilities to the MWC less often. Indeed, another prominent difference between the data and the theory is that there is no evidence that proposers endogenously adjust for exogenous advantages. In turn, this means that exogenous advantages will eventually be reflected in expected payoffs.

The findings raise new questions for future research in the area. One approach is to focus on the empirical difference between non-proposer allocations and expected payoffs, since it is this difference that triggers the most substantial deviation from the SSSPE prediction. A first hypothesis is that while non-proposer allocations are readily observable, expected payoffs require a calculation. In the design of the weighted voting experiment I selected extreme values for recognition probabilities in one treatment ( $W V$ Near Even) in order to make a key component of expected payoffs very salient. However, the findings suggest that perhaps an even more explicit manipulation is required to rule out this hypothesis.

Another hypothesis is that there is a norm on what is acceptable pay for a non-proposer. The share that non-proposers receive is between 80 and $90 \%$ of the equal division benchmark, which is consistent with behavior reported in homogeneous multilateral bargaining experiments (Fréchette et al. 2003) and bilateral bargaining experiments (see Roth 1995). The additional piece of evidence that this experiment offers is that such a norm would be independent of exogenous differences such as different recognition probabilities. ${ }^{52} \mathrm{An}$ implicit assumption behind this hypothesis is that if non-proposers were offered the SSSPE continuation values, they would vote against it. Unfortunately, it is not possible to test this assumption with the current data as only very few proposals are close to the SSSPE. A laboratory manipulation that guarantees introduction of such proposals may be a useful first step to testing necessary conditions for the hypothesis.

\footnotetext{
${ }^{52}$ Theoretically, the norm can be represented with an additional constraint such that if the continuation value is lower than the norm, the constraint is binding. Clearly, the theory would also need to explain what the determinants of the norm are.
} 
Support for the main hypothesis indicates that if there were a preference for an even distribution of resources, there could be a welfare gain of allocating proposal power to the house in a bicameral system. To provide a measure of the gain, I use a standard welfare function that is maximized when the distribution of resources is even. Specifically, welfare is a quadratic function of the difference between the allocation to district $i\left(x_{i}\right)$ and an equal split $\left(\frac{1}{n}\right): W=-\sum_{i}\left(x_{i}-\frac{1}{n}\right)^{2}$. In the SSSPE, $W$ will be negative because one district will be proposing and some districts will not be included in the MWC. For the parametrization, the expected welfare loss when proposal power is in the senate is $18 \%$ higher than when it is in the house. ${ }^{53}$

Even if I focus on proposals that involve MWCs, the welfare loss in the data is lower than predicted. ${ }^{54}$ The main reason is that proposer and non-proposer allocations are closer to each other than predicted. Using figures from Table 4, the welfare loss when proposal power is in the house (senate) is $58 \%(50 \%)$ of the theoretical prediction. In the data, the welfare loss when proposal power is in the senate is only $2 \%$ higher than when the proposer is selected from the house. In other words, the actual gain from shifting proposal power to the house is approximately a tenth of the predicted gain.

Moreover, the setup in this paper is a purely redistributive one, but when there are spillovers across districts the welfare loss of a small-state bias can be smaller. In fact, one alternative for future experimental research consists in expanding the environment to public goods that are not divisible at the district level, as in the setup of Kalandrakis (2004).

\section{References}

Agranov, M., Tergiman, C., 2014. Communication in multilateral bargaining. Journal of Public Economics 118, 75-85.

Ansolabehere, S., Snyder, J., Ting, M., 2003. Bargaining in bicameral legislatures: When and why does malapportionment matter? American Political Science Review 97 (03), $471-481$.

Atlas, C. M., Gilligan, T. W., Hendershott, R. J., Zupan, M. A., June 1995. Slicing the

\footnotetext{
${ }^{53}$ When proposal power is in the house, the SSSPE predicts that one district will receive a $\frac{3}{5}$ share, that two will get $\frac{1}{5}$ and that the other two get zero. Hence, welfare ex-post will be -0.240 . When proposal power is in the senate the outcome depends on who is selected as a proposer. When the proposer is from an $\mathrm{S}$ state: the proposer receives a $\frac{5}{7}$ share and two L districts receive a $\frac{1}{7}$ share. The welfare loss in this case would be -0.351 . When the proposer is from an L state: two L districts will receive a $\frac{5}{14}$ share and one $\mathrm{S}$ district receives $\frac{1}{7}$. The welfare loss would be -0.144 . But the proposer is from an S state with $\frac{2}{3}$ probability, so that expected welfare is $-0.282,18 \%$ higher than the welfare loss when proposal power is in the house.

${ }^{54}$ Including proposals that involve an equal split would make welfare losses smaller.
} 
federal government net spending pie: Who wins, who loses, and why. The American Economic Review 85 (3), 624-629.

Baron, D., Ferejohn, J., 1989. Bargaining in legislatures. The American Political Science Review, 1181-1206.

Barrett, G. F., Donald, S. G., 2003. Consistent tests for stochastic dominance. Econometrica 71 (1), 71-104.

Christiansen, N., Georganas, S., Kagel, J. H., 2014. Coalition formation in a legislative voting game. American Economic Journal: Microeconomics 6 (1), 182-204.

Diermeier, D., Morton, R., 2004. Proportionality versus perfectness: Experiments in majoritarian bargaining" in social choice and strategic behavior: Essays in the honor of jeffrey s. banks, ed. by david austen-smith and john duggan. berlin: Springer.

Drouvelis, M., Montero, M., Sefton, M., 2010. Gaining power through enlargement: Strategic foundations and experimental evidence. Games and Economic Behavior 69 (2), 274-292.

Fischbacher, U., 2007. z-tree: Zurich toolbox for ready-made economic experiments. Experimental Economics 10 (2), 171-178.

Fréchette, G., Kagel, J., Lehrer, S., 2003. Bargaining in legislatures: An experimental investigation of open versus closed amendment rules. American Political Science Review 97 (02), 221-232.

Fréchette, G., Kagel, J., Morelli, M., 2005a. Behavioral identification in coalitional bargaining: An experimental analysis of demand bargaining and alternating offers. Econometrica 73 (6), 1893-1937.

Fréchette, G., Kagel, J., Morelli, M., 2005b. Nominal bargaining power, selection protocol, and discounting in legislative bargaining. Journal of Public Economics 89 (8), 1497-1517.

Fréchette, G., Kagel, J., Morelli, M., 2010. Pork versus public goods: an experimental study of public good provision within a legislative bargaining framework. Economic Theory, 1-22.

Fréchette, G. R., 2015. Laboratory experiments: Professionals versus students. in Handbook of Experimental Economic Methodology, ed. by Guillaume R. Fréchette and Andrew Schotter, Oxford University Press, pp: 360-390.

Hauk, W., Wacziarg, R., 2007. Small states, big pork. Quarterly Journal of Political Science $2(1), 95-106$. 
Kagel, J., Sung, H., Winter, E., 2010. Veto power in committees: an experimental study. Experimental Economics 13 (2), 167-188.

Kalandrakis, T., 2004. Bicameral winning coalitions and equilibrium federal legislatures. Legislative Studies Quarterly 29 (1), 49-79.

Knight, B., 2008. Legislative representation, bargaining power and the distribution of federal funds: Evidence from the us congress. The Economic Journal 118 (532), 1785-1803.

Lee, F., 2000. Senate representation and coalition building in distributive politics. American Political Science Review, 59-72.

Lee, F., Oppenheimer, B., 1999. Sizing up the Senate: The unequal consequences of equal representation. University of Chicago Press.

Lizza, R., 2009. The gatekeeper. The New Yorker, March 2.

Lyptak, A., March 11, 2013. Smaller states find outsize clout growing in senate. The New York Times.

MacGillis, A., August 9, 2009. In the senate, small states wield outsize power. The Washington Post.

McKelvey, R., 1991. An experimental test of a stochastic game model of committee bargaining. Contemporary Laboratory Research in Political Economy.

Roth, A. E., 1995. Handbook of Experimental Economics. Princeton University Press, Princeton, Ch. Bargaining Experiments, pp. 253-348.

Samuels, D., Snyder, R., 2001. The value of a vote: malapportionment in comparative perspective. British Journal of Political Science 31 (4), 651-671.

Siegel, S., Harnett, D., 1964. Bargaining behavior: A comparison between mature industrial personnel and college students. Operations Research 12 (2), 334-343.

Snyder, J., Ting, M., Ansolabehere, S., 2005. Legislative bargaining under weighted voting. The American Economic Review 95 (4), 981-1004.

Tergiman, C., 2015. Institution design and public good provision: an experimental study of the vote of confidence procedure. Experimental Economics 18 (4), 718-730. 